\title{
Missing upper incisors: a retrospective study of orthodontic space closure versus implant
}

\author{
Abdolreza Jamilian ${ }^{1 *}$, Letizia Perillo ${ }^{2}$ and Marco Rosa ${ }^{3}$
}

\begin{abstract}
Background: The aim of this retrospective study was to compare the esthetic, periodontal, and functional outcomes of orthodontic space closure versus implant substitution in patients with missing maxillary incisors 5 years after completion of treatment.

Methods: The study group consisted of ten patients treated with orthodontic space closure (six males, four females, mean age $19 \pm 2.1$ years at the completion of treatment) and ten patients treated with implant insertion (five males, five females, mean age $20 \pm 1.4$ years at the time of implant insertion). Tooth mobility, plaque index, probing depth, infraocclusion, open gingival embrasure (black triangle), and temporomandibular joint function were recorded at the 5.6 years follow-up. Self-perceived dental esthetic appearance was also evaluated through a visual analog scale (VAS) questionnaire. T-test was used to evaluate the data.
\end{abstract}

Results: All patients were equally satisfied with the appearance of their teeth $5.6 \pm 0.4$ years after the completion of treatment. No statistically significant differences were found in relation to the VAS scores of the subjects $(P<0.857)$. No significant differences were found in tooth mobility, plaque index $(P<0.632)$, and the prevalence of signs and symptoms of temporomandibular disorders. However, significant infraocclusion was noticed in all implant patients $(P<0.001)$. Probing depth was also significantly higher in implant patients $(P<0.001)$.

Conclusions: Orthodontic space closure and implant of missing maxillary incisors produced similar, well-accepted esthetic results. None of the treatments impaired temporomandibular joint function. Nevertheless, infraocclusion was evident in implant patients. Space closure patients also showed better periodontal health in comparison with implant patients.

Keywords: Implant; Orthodontic space closure; Missing maxillary incisor; Infraocclusion; Periodontal health

\section{Background}

The absence of upper incisors is a serious problem and often needs a challenging treatment. The treatment alternatives of missing upper incisors include orthodontic space closure, resin-bonded bridgework, osseointegrated implants, removable partial dentures, and autotransplantation of developing premolars [1-7]. Although each of these methods is a viable treatment option, implant insertion and space closure are more popular among clinicians.

Implant substitution is considered an optimal solution considering the possibility of obtaining an ideal occlusion and the indisputable advantage of avoiding any

\footnotetext{
* Correspondence: info@jamilian.net

'Department of Orthodontics, Dental Branch, Craniomaxillofacial Center Islamic Azad University, No 2713, Vali Asr St., Tehran 1966843133, Iran Full list of author information is available at the end of the article
}

damage to the adjacent teeth $[1,8]$. Orthodontic space closure, by mesial movement of the adjacent teeth, also provides satisfactory esthetic and functional long-term results $[9,5,10]$. One of the major advantages of space closure is that treatment is finished immediately after orthodontics and, in the case of adolescents, there is no necessity of waiting years until the 'end of growth' to replace the missing tooth. Moreover, the result is natural and all the changes in the long term will also be natural, unlike what could happen in the presence of a foreign body.

The aim of this study was to examine and compare, 5 years post treatment, the esthetic outcomes, function, and periodontal health in two groups of subjects with one or two missing maxillary incisors and

\section{Springer}


Table 1 Distribution of age, sex, and left or right missing teeth in the OSC and implant groups

\begin{tabular}{|c|c|c|c|c|}
\hline \multicolumn{2}{|l|}{$\begin{array}{l}\text { Treatment } \\
\text { group }\end{array}$} & $\begin{array}{l}\text { OSC } \\
\text { group }\end{array}$ & $\begin{array}{l}\text { Implant } \\
\text { group }\end{array}$ & Significance \\
\hline \multicolumn{2}{|c|}{$\begin{array}{l}\text { Age at the time of } \\
\text { treatment completion }\end{array}$} & $19 \pm 2.1$ & $20 \pm 1.4$ & NS \\
\hline \multirow[t]{2}{*}{ Gender } & Male & 6 & 5 & NS \\
\hline & Female & 4 & 5 & NS \\
\hline \multirow[t]{2}{*}{ Lateral incisor } & Left & 3 & 1 & NS \\
\hline & Right & 4 & 3 & NS \\
\hline \multirow[t]{2}{*}{ Central incisor } & Left & 4 & 4 & NS \\
\hline & Right & 6 & 6 & NS \\
\hline \multicolumn{2}{|l|}{$\begin{array}{l}\text { Treatment time } \\
\text { (months) }\end{array}$} & $29 \pm 7$ & $18 \pm 4$ & $P<0.001$ \\
\hline
\end{tabular}

OSC, orthodontic space closure; NS, not significant.

treated either with implant substitution or orthodontic space closure.

\section{Methods}

This retrospective observational study was carried out in accordance with the ethical standards set forth in the 1964 Declaration of Helsinki. Informed written consent was obtained from each patient and a parent or guardian.

Twenty-six patients with missing maxillary incisors, who were treated by one orthodontist between 2004 and 2006 in two centers, were all invited to a followup examination. One of the patients was omitted from the study because she could have only been treated by means of implant insertion. Five of the patients refused to attend. Out of the 20 remaining patients, 10 were treated by implant insertion and 10 by orthodontic space closure.

The selection criteria included patients who had the following:

- Congenital absence of the maxillary central and/or lateral incisor.

- Patients treated with orthodontic space closure and/ or implant.

Table 2 Clinical records of periodontal states

\begin{tabular}{ll}
\hline Index & Assessment method \\
\hline Tooth mobility & Mobility more than $1 \mathrm{~mm}$ was recorded \\
Probing depth & Pockets exceeding $3 \mathrm{~mm}$ were recorded \\
Infraocclusion & Infraocclusion exceeding $1 \mathrm{~mm}$ was recorded \\
TMD & Tooth clenching, grinding, and TMJ sounds \\
& were recorded \\
\hline
\end{tabular}

TMD, temporomandibular joint dysfunction; TMJ, temporomandibular joint.

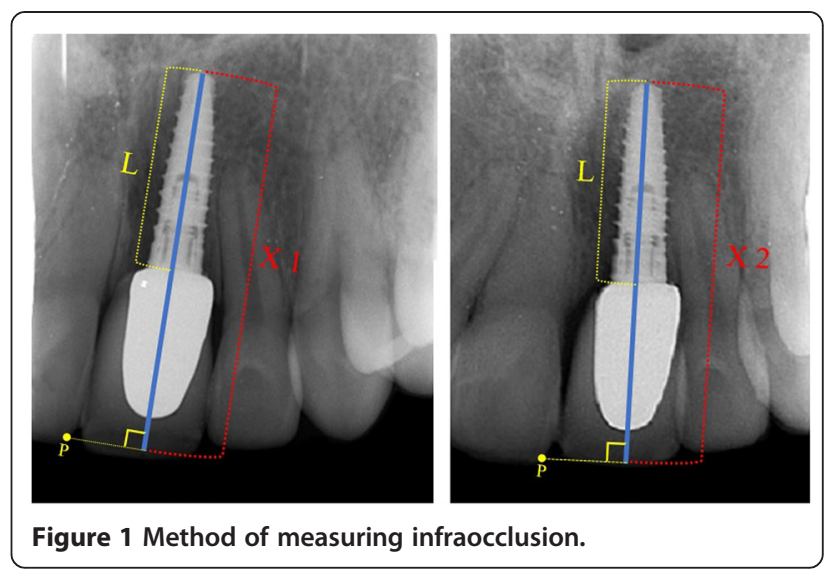

- Patients who could have been treated by either space closure or implant insertion.

- Patients not treated with autotransplantation or crown bridge.

- No periodontal breakdown or history of periodontal disease.

The implant group (IG) consisted of ten patients (five males, five females, mean age $20 \pm 1.4$ years at the time of implant insertion). All the implants were of the same type and were inserted by the same surgeon. Fourteen teeth including four lateral and ten central maxillary incisors were totally missing in the implant group. The average treatment time of these patients was $18 \pm 4$ months. The orthodontic space closure (OSC) group consisted of ten patients (six males, four females, mean age $19 \pm 2.1$ years at the completion of treatment). Seventeen teeth including

Table 3 Questionnaire for assessing TMD

\begin{tabular}{l} 
Severity of occurrence \\
\hline 1. Do you have difficulty in opening \\
your mouth? \\
2. Do you have difficulty in moving or \\
using your jaw? \\
3. Do you have tenderness or muscular \\
pain when chewing? \\
4. Do you have frequent headaches? \\
5. Do you have neck aches or \\
shoulder pain? \\
6. Do you have pain in or about the ears? \\
7. Are you aware of noises in the jaw joints? \\
8. Do you consider your bite "normal"? \\
9. Do you use only one side of your \\
mouth when chewing? \\
10. Do you have morning facial pain?
\end{tabular}


Table 4 Comparison of parameters between implant and space closure groups

\begin{tabular}{llllll}
\hline Recorded scores & $\begin{array}{l}\text { Tooth mobility } \\
\text { (number of teeth) }\end{array}$ & $\begin{array}{l}\text { Probing depth } \\
\text { (number of teeth) }\end{array}$ & $\begin{array}{l}\text { Infraocclusion } \\
\text { (number of teeth) }\end{array}$ & $\begin{array}{l}\text { Plaque index } \\
\text { (mean } \pm \text { SD) }\end{array}$ & $\begin{array}{l}\text { TMD } \\
\text { (mean } \pm \text { SD) }\end{array}$ \\
\hline Implant group & 1 & 12 & 14 & $3.1 \pm 1.2$ & $1.3 \pm 1.1$ \\
OSC group & 0 & 3 & 0 & $2.9 \pm 1.1$ & $1.5 \pm 1.03$ \\
$P$ value & NS & $0.001^{*}$ & $0.001^{*}$ & 0.632 & 0.605 \\
\hline
\end{tabular}

*Level of significance set at $P<0.05$. TMD, temporomandibular joint dysfunction; SD, standard deviation; OSC, orthodontic space closure.

seven lateral and ten central maxillary incisors were totally missing in the OSC group. The average treatment time of these patients was $29 \pm 7$ months (Table 1). For retention, upper and lower Hawley retainers were worn by all the patients for 1 year.

The follow-up records were taken 5 years or more after the completion of treatment (mean interval was $5.6 \pm 0.4$ years).

Tooth mobility (TM) [11], plaque index (PI) [12,13], probing depth (PD), infraocclusion (I), open gingival embrasure (black triangle) [14], and temporomandibular joint dysfunction (TMD) of the patients were recorded at the follow-up examinations (Table 2).

Probing depth was recorded at four sites for each upper central and lateral incisor with a periodontal probe. Identical intra-oral radiographs, taken with the 'parallel technique', were used for assessment of infraocclusion. Evaluation of the image distortion was done by measuring the length of the implant (L) as it appears on the radiography and comparing it to the real length of the implant (Figure 1). In order to evaluate infraocclusion, a reference point (p) was selected on the intersection between the incisal and mesial borders of the tooth adjacent to the implant. Afterwards, a line was drawn from this point perpendicular to the longitudinal axis of the implant creating the projection of $\mathrm{p}$. The distance between the projection of $\mathrm{p}$ and the apex of the implant was measured, and the difference between this distance after the completion of treatment and follow-up examination was recorded as infraocclusion $(X 2-X 1)$ (Figure 1). The distance of the alveolar crest to the contact point of the teeth was used to evaluate the presence of an open embrasure (black triangle). A distance of more than $5 \mathrm{~mm}$ was considered as black triangle [14].

The prevalence of signs and symptoms of TMD was assessed by means of an anamnestic questionnaire [15] (Table 3). A score ' 0 ' indicated the absence of symptoms, whereas ' 1 ' was given for a report of an occasional occurrence. Grade 2 indicated the presence of symptoms, and a score of ' 3 ' was used to indicate severe pain or bilateral symptoms. The sum of the scores was used to classify the sample into four categories: (1) from 0 to 3 , TMD free; (2) from 4 to 8, mild TMD; (3) from 9 to 14 , moderate TMD; and (4) from 15 to 23, severe TMD. Plaque was measured by the plaque index developed by
Quigley and Hein [12] and modified by Turesky et al. [13]. The scoring system is as follows: $0=$ no plaque, $1=$ separate flecks of plaque at the cervical margin of the tooth, $2=\mathrm{a}$ thin continuous band of plaque at the cervical margin, $3=$ a band of plaque wider than $1 \mathrm{~mm}$ but covering less than one third of the crown, $4=$ plaque covering at least one third but less than two thirds of the crown, $5=$ plaque covering two thirds or more of the crown. None of the patients had systemic diseases or long-term pharmacological treatment until the end of follow-up studies.

Patient satisfaction was assessed using the visual analog scale (VAS) $[16,17]$. The subjects were asked to record their happiness with their dental and facial appearance on a 10-cm VAS having phrases 'very dissatisfied' (score 0) on the left end and 'very satisfied' (score 10) on the right end.

Each patient was examined by two examiners in two sessions with an interval of 1 week. The inter-examiner agreement was calculated through kappa analysis. A kappa value of 0.96 showed perfect agreement. $T$-test was used to evaluate the data of the study.

\section{Results}

Tables 4 and 5 show the results $5.6 \pm 0.4$ years after treatment. Increased mobility was noticed in only one implant, but no tooth mobility was present in any of the OSC patients. More than $3 \mathrm{~mm}$ increase of probing depth was found in 12 implants, while it increased more than $3 \mathrm{~mm}$ in only 3 teeth in the OSC group $(P<0.001)$. The vertical step measured on radiographs of implant patients varied between 1.2 and $1.6 \mathrm{~mm}$, which showed that all implant-supported teeth had increased infraocclusion of more than $1 \mathrm{~mm}$, while none of the OSC patients showed infraocclusion $(P<0.001)$ (Figure 1). Black triangle was seen in one of the implant patients and three of the OSC patients.

\section{Table 5 Patient satisfaction assessed by visual analog scale (VAS) after 5 years since the completion of} treatment

\begin{tabular}{llll}
\hline & $\begin{array}{l}\text { Implant group } \\
\text { Mean } \pm \text { SD }\end{array}$ & $\begin{array}{l}\text { OSC group } \\
\text { Mean } \pm \text { SD }\end{array}$ & P value \\
\hline VAS scores & $8.7 \pm 1.3$ & $8.8 \pm 1.2$ & 0.857 \\
\hline
\end{tabular}

OSC, orthodontic space closure; SD, standard deviation. 


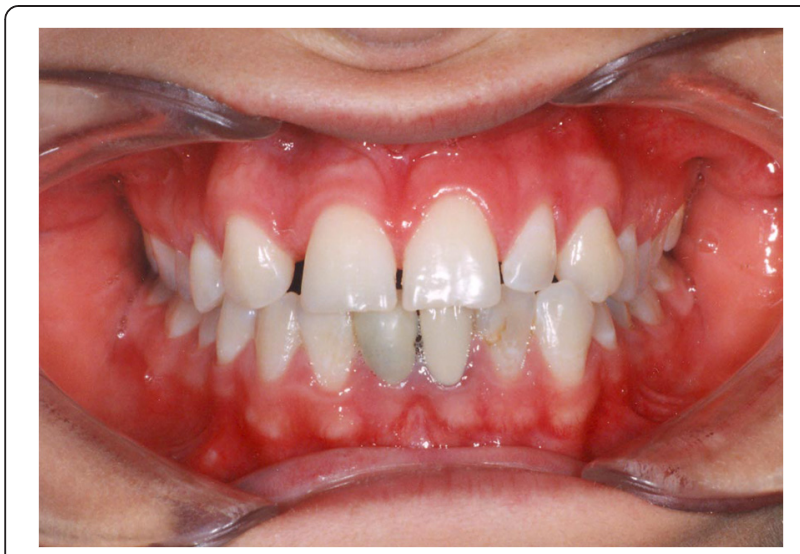

Figure 2 A patient with a missing maxillary lateral incisor.

No signs and symptoms of temporomandibular joint dysfunction including history of headache, locking, difficulty in opening/closing mouth, and tooth clenching were noticed in any of the patients, and $T$-test showed that there were no statistically significant differences between the two groups $(P<0.605)$. Five years after the completion of treatment, the plaque indexes of the implant and OSC patients were $3.1 \pm 1.2$ and $2.9 \pm 1.1$, respectively $(P<0.632)$ (Table 4$)$.

VAS scores of $8.7 \pm 1.3$ and $8.8 \pm 1.2$ were recorded for the implant and OSC patients, subjectively. The scores which ranged from 7 to 10 showed that both groups were almost equally satisfied with the appearance of their teeth after 5 years. $T$-test did not show any statistically significant difference between the two groups (Table 5).

Figures 2 and 3 show a patient with a missing upper lateral incisor, and Figures 4 and 5 show the same patient 5 years after implant insertion. Figures 6 and 7 show a patient with missing maxillary lateral incisors treated by orthodontic space closure, and Figures 8 and 9 show the same patient 5 years after the completion of treatment.

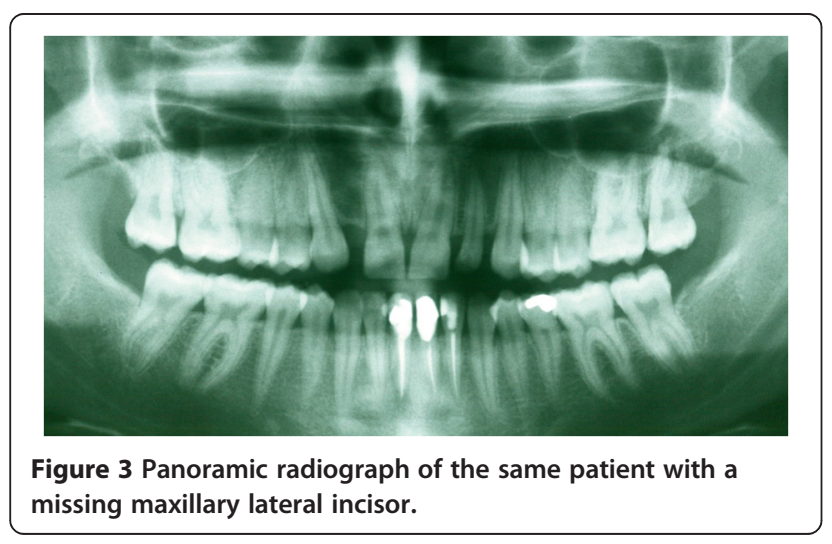

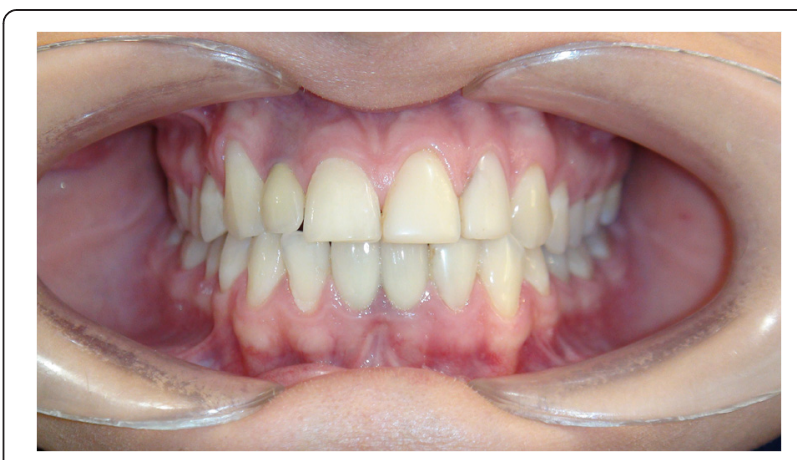

Figure 4 The same patient 5 years after implant insertion.

\section{Discussion}

The present retrospective study shows that both treatment modalities resulted in satisfactory and well-accepted esthetic outcomes after 5 years. However, infraocclusion and increased probing depth were seen in the implant patients.

These findings correspond to the findings of Bernard et al. [18], Kuijpers et al. [19], and Jemt et al. [20] who reported that even if the implant is inserted after 19 years of age, the adjacent teeth and surrounding alveolar bone may continue to develop vertically and may continue to erupt resulting in infraocclusion of the implant restoration, i.e., a discrepancy between the gingival margin of the implant restoration and the gingival margin of the adjacent natural teeth may appear in a few years after treatment, and the implant becomes submerged. In cases where the upper and lower incisors are not in contact, the resulted extrusion might be $0 / 2$ to $0 / 3 \mathrm{~mm}$ per year. Implants behave like ankylosed teeth, and their position cannot change in contrast to their neighboring natural teeth; therefore, even small tooth movements of adjacent teeth after implant placement can cause esthetic problems [21-23]. The disharmonious levels of the gingival margins resulting from infra-positioned implant restorations are an evident disadvantage in patients with a high smile line. Thus, 'gummy smile', or patients who show the gingival margins, is in our opinion a contraindication for implant substitution of the upper incisors [5].

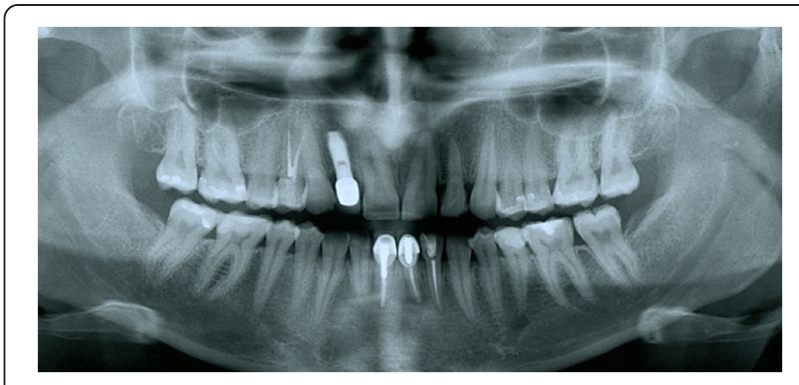

Figure 5 Panoramic radiograph of the same patient 5 years after implant insertion. 


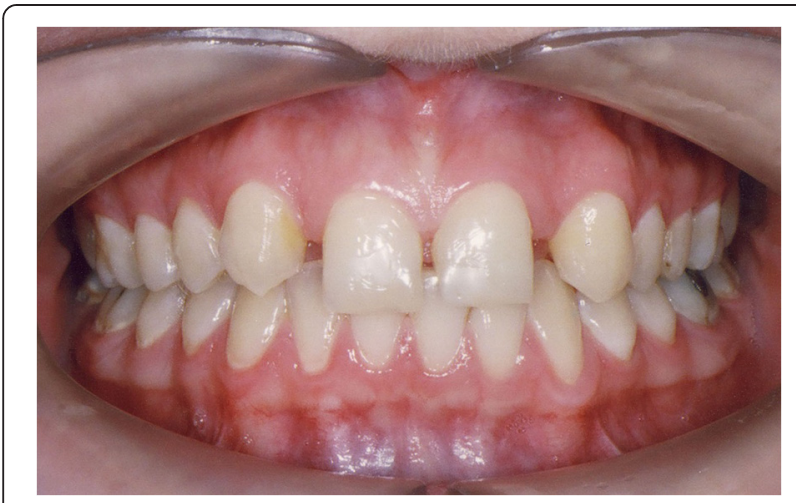

Figure 6 A patient with missing maxillary lateral incisors.

Implant substitution could have other disadvantages. It has been shown that most implant crowns show some lack of interdental papillary fill, particularly on the distal papilla [24]. Furthermore, blue coloring of the labial gingiva has been reported in above more than $50 \%$ of single-implant crowns at 4-year follow-ups [25]. Periimplantitis, gingivitis, increased probing depth, bleeding on probing, and progressive loss of marginal bone support at the buccal aspect of the implant have also been reported in implants [22,24,26,27].

Finally, the biggest disadvantage of the implant alternative is that adolescents must wait many years after orthodontic treatment before the implant insertion. During this interim time, patients must use temporary restorations that often create many different problems and replacements. Nevertheless, the comparatively shorter and easier treatment makes implants a favorable treatment option for substituting missing teeth.

In contrast to the abovementioned disadvantages related to implants, orthodontic space closure is a viable and safe procedure that could provide better long-term results [9]. Moreover, none of the abovementioned disadvantages have been noticed in orthodontic space closure [28,29]. Nevertheless, the applicability of orthodontic space closure for missing incisors is sometimes questioned. Concerns may be

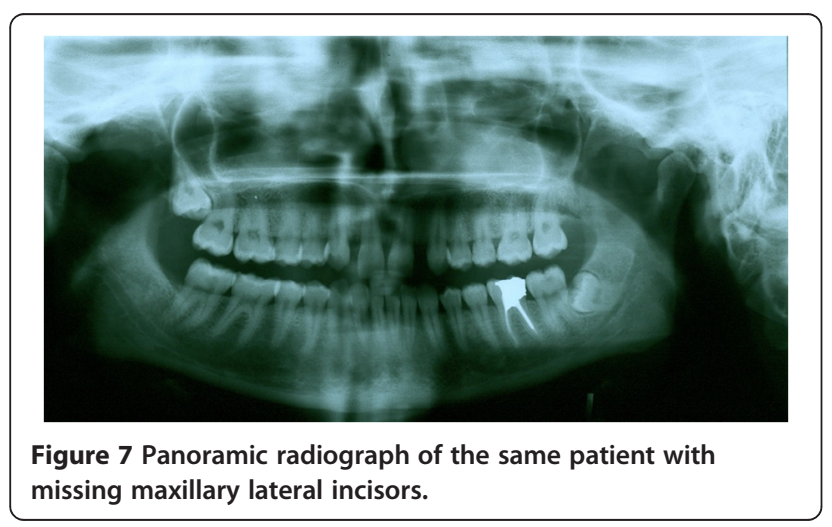

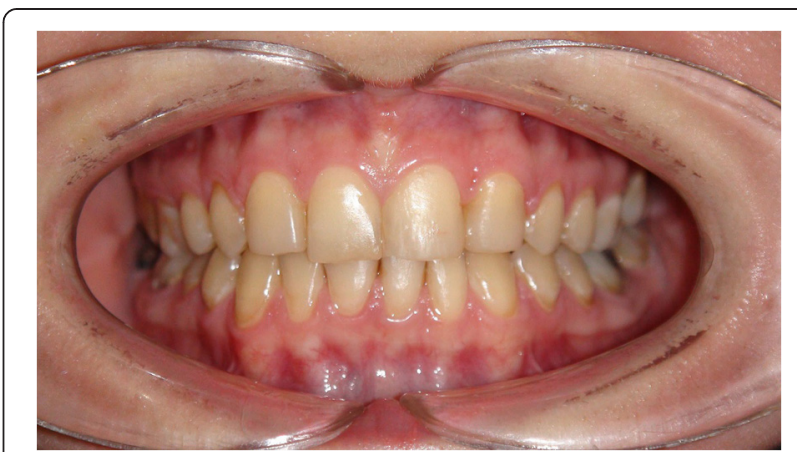

Figure 8 The same patient 5 years after orthodontic space closure.

expressed related to the treatment complexity, the risk for space reopening, the questioned increased functional load on the first premolar roots, and the quality of the esthetic result especially in the case of a lateral incisor's root supporting the larger crown of a central incisor [30].

The main advantages of the space closure alternative compared to implants can be highlighted as follows:

- Treatment is finished immediately after orthodontics. This is for crucial interest when treating adolescent patients.

- Periodontal problems will not develop in space closure because the tooth has moved along with its bone and surrounding tissues.

- Space closure provides patients with better longterm esthetic results in the transition area, due to lack of bone loss and periodontal problems.

- Prosthetic replacement of the lost incisor also by partial denture or bonded bridges could need further treatments to replace the restorations or to fix possible periodontal breakdown.

Allocation of patients in this study and comparing their treatment effects could be considered as one of the weaknesses of the current study because the patients were allocated to the implant or the OSC group based on the space between their teeth. However, it should be considered that the results of the current study can assist in treatment

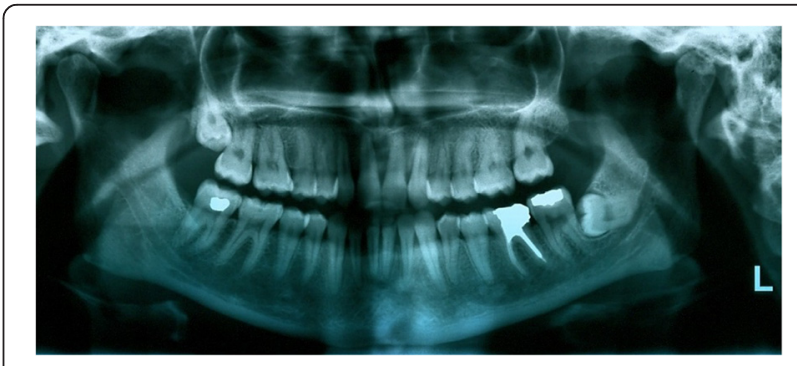

Figure 9 Panoramic radiograph of the same patient 5 years after orthodontic space closure. 
planning for borderline cases who could be treated by either implant insertion or orthodontic space closure.

\section{Conclusions}

Five years after treatment, orthodontic space closure and implant substitution of missing maxillary incisors produced similar satisfactory esthetic results. Neither of the treatments impaired temporomandibular joint function. However, orthodontic space closure patients had better periodontal health in comparison with implant substitution patients. Furthermore, infraocclusion more than $1 \mathrm{~mm}$ was noticed in all the implant patients.

\section{Competing interests}

The authors declare that they have no competing interests.

\section{Authors' contributions}

AJ was responsible for the study design, administration, recruitment and treatment, drafting, writing and revising the report, critical revision, and fina approval of the article. MR and LP were responsible for the study concept, analysis, data interpretation, critical revision, and final approval of the article. $\mathrm{AJ}$ is the guarantor. All authors read and approved the final manuscript.

\section{Author details}

${ }^{1}$ Department of Orthodontics, Dental Branch, Craniomaxillofacial Center Islamic Azad University, No 2713, Vali Asr St., Tehran 1966843133, Iran. ${ }^{2}$ Post Graduate Orthodontic Program, Department of Orthodontics, Second University of Naples, Via bellini, 44 80135, Naples, Italy. ${ }^{3}$ Post-graduate School in Orthodontics, Insubria University, P.za della Mostra, 19 38122, Trento, Italy.

Received: 11 October 2014 Accepted: 27 January 2015

\section{Published online: 25 February 2015}

\section{References}

1. Rupp RP, Dillehay JK, Squire CF. Orthodontics, prosthodontics, and periodontics: a multidisciplinary approach. Gen Dent. 1997;45(3):286-9.

2. Ghassemi M, Jamilian A, Fritz U, Riediger D, Ghassemi A. Orthodontic treatment after autotransplantation. Angle Orthod. 2011;81(4):721-5. doi:10.2319/102210-617.1.

3. Zachrisson BU, Stenvik A, Haanaes HR. Management of missing maxillary anterior teeth with emphasis on autotransplantation. Am J Orthod Dentofacial Orthop. 2004;126(3):284-8. doi:10.1016/S0889540604005244.

4. Rosa M, Olimpo A, Fastuca R, Caprioglio A. Perceptions of dental professionals and laypeople to altered dental esthetics in cases with congenitally missing maxillary lateral incisors. Prog Orthod. 2013;14:34. doi:10.1186/2196-1042-14-34

5. Zachrisson BU, Rosa M, Toreskog S. Congenitally missing maxillary lateral incisors: canine substitution. Point. Am J Orthod Dentofacial Orthop. 2011;139(4):434, 436, 438 passim. doi:10.1016/j.ajodo.2011.02.003.

6. Showkatbakhsh $\mathrm{R}$, Jamilian A. Opening or closing space for replacing upper incisors. Two case reports. Rev Esp Orthod. 2010;40:181-5.

7. Johal A, Katsaros C, Kuijpers-Jagtman AM, Angle Society of Europe membership. State of the science on controversial topics: missing maxillary lateral incisors-a report of the Angle Society of Europe 2012 meeting. Prog Orthod. 2013;14:20. doi:10.1186/2196-1042-14-20

8. Zachrisson BU. Planning esthetic treatment after avulsion of maxillary incisors. J Am Dent Assoc. 2008;139(11):1484-90.

9. Nordquist GG, McNeill RW. Orthodontic vs. restorative treatment of the congenitally absent lateral incisor-long term periodontal and occlusal evaluation. J Periodontol. 1975;46(3):139-43. doi:10.1902/jop.1975.46.3.139.

10. Robertsson S, Mohlin B. The congenitally missing upper lateral incisor. A retrospective study of orthodontic space closure versus restorative treatment. Eur J Orthod. 2000;22(6):697-710.

11. Mombelli A, van Oosten MA, Schurch Jr E, Land NP. The microbiota associated with successful or failing osseointegrated titanium implants. Oral Microbiol Immunol. 1987;2(4):145-51.

12. Quigley GA, Hein JW. Comparative cleansing efficiency of manual and power brushing. J Am Dent Assoc. 1962;65:26-9.
13. Turesky S, Gilmore ND, Glickman I. Reduced plaque formation by the chloromethyl analogue of victamine C. J Periodontol. 1970;41(1):41-3. doi:10.1902/jop.1970.41.41.41

14. Sharma AA, Park JH. Esthetic considerations in interdental papilla: remediation and regeneration. J Esthet Restor Dent. 2010;22(1):18-28. doi:10.1111/j.1708-8240.2009.00307.x.

15. Conti A, Freitas M, Conti P, Henriques J, Janson G. Relationship between signs and symptoms of temporomandibular disorders and orthodontic treatment: a cross-sectional study. Angle Orthod. 2003;73(4):411-7. doi:10.1043/0003-3219(2003)073<0411:RBSASO>2.0.CO;2.

16. O'Neill K, Harkness M, Knight R. Ratings of profile attractiveness after functional appliance treatment. Am J Orthod Dentofac Orthop. 2000:118(4):371-6. doi:10.1067/mod.2000.109492; discussion 7

17. Schabel BJ, McNamara Jr JA, Franchi L, Baccetti T. Q-sort assessment vs visual analog scale in the evaluation of smile esthetics. Am J Orthod Dentofac Orthop. 2009;135(4 Suppl):S61-71. doi:10.1016/j.ajodo.2007.08.019.

18. Bernard JP, Schatz JP, Christou P, Belser U, Kiliaridis S. Long-term vertical changes of the anterior maxillary teeth adjacent to single implants in young and mature adults. A retrospective study. J Clin Periodontol. 2004;31(11):1024-8. doi:10.1111/j.1600-051X.2004.00574.x.

19. Kuijpers MA, de Lange J, van Gool AV. [Maxillofacial growth and dental implants in the maxillary anterior region]. Ned Tijdschr Tandheelkd. 2006;113(4):130-3.

20. Jemt T, Ahlberg G, Henriksson K, Bondevik O. Changes of anterior clinical crown height in patients provided with single-implant restorations after more than 15 years of follow-up. Int J Prosthodont. 2006;19(5):455-61.

21. Spear FM, Mathews DM, Kokich VG. Interdisciplinary management of single-tooth implants. Semin Orthod. 1997;3(1):45-72.

22. Thilander B, Odman J, Lekholm U. Orthodontic aspects of the use of oral implants in adolescents: a 10-year follow-up study. Eur J Orthod. 2001;23(6):715-31.

23. Oesterle LJ, Cronin Jr RJ. Adult growth, aging, and the single-tooth implant. Int J Oral Maxillofac Implants. 2000;15(2):252-60.

24. Chang M, Wennstrom JL, Odman P, Andersson B. Implant supported single-tooth replacements compared to contralateral natural teeth. Crown and soft tissue dimensions. Clin Oral Implants Res. 1999;10(3):185-94.

25. Dueled E, Gotfredsen K, Trab Damsgaard M, Hede B. Professional and patient-based evaluation of oral rehabilitation in patients with tooth agenesis. Clin Oral Implants Res. 2009;20(7):729-36. doi:10.1111/j.16000501.2008.01698.x

26. Fransson C, Wennstrom J, Tomasi C, Berglundh T. Extent of peri-implantitisassociated bone loss. J Clin Periodontol. 2009;36(4):357-63. doi:10.1111/ j.1600-051X.2009.01375.x.

27. Paolantonio M, D'Ercole S, Pilloni A, D'Archivio D, Lisanti L, Graziani F, et al. Clinical, microbiologic, and biochemical effects of subgingival administration of a Xanthan-based chlorhexidine gel in the treatment of periodontitis: a randomized multicenter trial. J Periodontol. 2009;80(9):1479-92. doi:10.1902/jop.2009.090050.

28. Rosa M, Zachrisson BU. Integrating space closure and esthetic dentistry in patients with missing maxillary lateral incisors. J Clin Orthod. 2007:41(9):563-73. quiz 424.

29. Thordarson A, Zachrisson BU, Mjor IA. Remodeling of canines to the shape of lateral incisors by grinding: a long-term clinical and radiographic evaluation. Am J Orthod Dentofac Orthop. 1991;100(2):123-32.

30. Czochrowska EM, Skaare AB, Stenvik A, Zachrisson BU. Outcome of orthodontic space closure with a missing maxillary central incisor. Am J Orthod Dentofac Orthop. 2003;123(6):597-603. doi:10.1016/ S0889540603000544. 